\title{
Women's experience of acute skin toxicity following radiation therapy in breast cancer
}

This article was published in the following Dove Press journal: Journal of Multidisciplinary Healthcare

\author{
Eivind Richter Andersen ${ }^{1,2}$ \\ Grethe Eilertsen ${ }^{3}$ \\ Aud Mette Myklebust ${ }^{2}$ \\ Siren Eriksen ${ }^{3,4}$ \\ 'Department of Radiotherapy, \\ Division of Hematology and Oncology, \\ Stavanger University Hospital, \\ Stavanger, Norway; ${ }^{2}$ Department \\ of Optometry, Radiography and \\ Lighting Design, University College \\ of Southeast Norway, Drammen, \\ Norway; ${ }^{3}$ Department of Nursing and \\ Health Sciences, Faculty of Health and \\ Social Sciences, University College \\ of Southeast Norway, Drammen, \\ Norway; ${ }^{4}$ Norwegian National \\ Advisory Unit on Ageing and Health, \\ Vestfold Hospital Trust, Tønsberg, \\ Norway
}

Purpose: Acute skin toxicity is experienced by $70 \%-100 \%$ of patients receiving radiation therapy following breast cancer. Most studies focus on skin appearances and treatment of such reactions, not the experience. Increased knowledge about patients' experience will contribute to provide tailored patient care. Thus, the purpose was to investigate patients' experiences of acute skin toxicity following radiation therapy for breast cancer.

Patients and methods: Semi-structured in-depth interviews were conducted with seven women, 2-3 weeks post-treatment. Five broad areas of inquiry were investigated: 1) experiences from the development of skin reactions; 2) experiences in day-to-day life; 3) coping strategies; 4) experiences of information; and 5) experiences from the aftercare. The interviews were analyzed in line with qualitative content analysis.

Results: The main theme "Not so bad itself, but it comes on top of everything else" was identified, based upon three categories: 1) unique experience of the skin; 2) it is something about the psychological aspect; and 3) experience of information.

Conclusion: Acute skin toxicity following breast cancer treatment may affect many dimensions of patients' lives. Experiences are complex, individual, and not necessarily consistent with visible changes of the skin. A holistic approach is necessary to provide treatment and support according to patients' individual needs.

Keywords: supportive care, acute skin toxicity, oncology, neoplasm

\section{Introduction}

Acute skin toxicity is a common side effect of radiation therapy that is experienced by $70 \%-100 \%$ of patients treated for early-stage breast cancer. ${ }^{1-5}$ Reactions occur within 1-4 weeks of treatment and range from erythema to dry or wet desquamation; ulceration may occur in more severe cases. ${ }^{6}$ Skin toxicity may affect women for a long time post-treatment. Knobf and Sun found that $>50 \%$ of participants in their study reported sensation changes in the breast 3 months post-treatment, including numbness, tingling, burning, and increased sensitivity. ${ }^{7}$ Sjovall et al found that $55 \%$ of patients still had symptoms such as dry, red, and itching skin at 6 months post-treatment. ${ }^{8}$

A study investigating the psychological support needs of patients with cancer reported that $25 \%$ of female patients and $10 \%$ of male patients needed more psychological support. ${ }^{9}$ Younger patients were also more likely to desire psychological support. Hormone therapy was associated with higher support needs, whereas radiation therapy was associated with lower support needs. These findings may be explained by the effect of hormone therapy combined with less intensive treatment. Less desire

\footnotetext{
Correspondence: Eivind Richter Andersen

Department of Radiotherapy, Division of Hematology and Oncology, Stavanger University Hospital, PO Box 8100, 4068 Stavanger, Norway

Tel +475 I5I 9030

Fax +475 I5। 8952

Email Eivind.richter.andersen@sus.no
} 
for psychological support during radiation therapy may also be explained by daily contact with health care professionals, which may offer a feeling of security and support. ${ }^{9}$

Evaluation of skin toxicity is traditionally based on visual observations. ${ }^{1,4,10}$ No consensus about how to grade or treat such reactions exists. ${ }^{2,3,6}$ In addition, few studies have focused on patients' experiences of skin reactions. In 1999, Noble-Adams recommended a more holistic approach when evaluating skin reactions, including subjective symptoms such as burning sensations, itching, and impact on day-today activities. ${ }^{10}$ However, in a systematic review of breast cancer and skin toxicity, patient-rated measures were found in only $9 \%$ of the reviewed abstracts $(n=237)$. There is a lack of literature discussing the experience of skin toxicity in patients with breast cancer compared with other cancerrelated symptoms, side effects, and quality of life. ${ }^{4}$

A study investigating skin toxicity based on interviews during the last week of treatment described how skin toxicity may affect life across multiple dimensions, including physical discomfort, body image disturbance, emotional distress, and impairment of day-to-day function. Furthermore, individual differences may also affect women's experiences of skin toxicity. ${ }^{5}$

Studies have demonstrated that the need for information is strongest before radiation therapy. ${ }^{11,12}$ However, acute skin toxicity is expected to escalate post-treatment. ${ }^{13}$ It is not usual practice to offer systematic aftercare during this period, which may lead to suboptimal management of patients' skin reactions. ${ }^{14}$

In general, there is a lack of empirical literature describing experiences in the early months after primary medical treatment. ${ }^{15}$ To our knowledge, no studies investigating in-depth experiences of skin toxicity following radiation therapy for early-stage breast cancer have been conducted.

\section{Purpose}

The purpose of this study was to investigate patients' experiences of acute skin toxicity during treatment and immediately after completion of radiation therapy for breast cancer.

\section{Patients and methods Design}

This qualitative study used an explorative design with in-depth individual participant interviews. Qualitative interviews aim to gain knowledge about the experiences of participants in relation to a particular phenomenon. ${ }^{16}$ In this case, the phenomenon is acute skin toxicity. Content analysis was conducted, consistent with Graneheim and Lundman. ${ }^{17}$ This is a well-known method for analyzing qualitative interviews. ${ }^{18,19}$

\section{Inclusion and recruitment}

According to the inclusion criteria (Table 1), a purposeful sample of participants was recruited in a Norwegian hospital from June to December 2014. In order to ensure sufficient data, a consecutive consideration of the sample size was made. Thus, interviews were conducted and transcribed (by ERA) before including another patient. Interviews were scheduled $\sim 2$ weeks post-treatment. Other eligible patients were not invited to participate during this period. The procedure was repeated until no new data appeared.

Patients experiencing skin toxicity at the beginning of their last week of treatment were informed about the study by a dedicated radiation therapist and provided with a consent form.

Twelve patients treated with Varian Truebeam ${ }^{\circledR}$ Radiotherapy system (Varian Medical Systems, Palo Alto, CA, USA) were asked to participate. On their last day of treatment, the first author provided further information about the study and obtained written consent. Two patients could not participate owing to logistic difficulties, one patient was too tired after treatment, and two patients needed to travel posttreatment. Therefore, seven women aged 31-71 years were included in the study sample. Participant characteristics are presented in Table 2.

Robust qualitative research does not exaggerate the extent of the material. Too large an amount of material might lead to superficial analysis. ${ }^{16}$ During the recruitment process, the sample size was consecutively considered in terms of the extent of new knowledge provided. Data

Table I Inclusion and exclusion criteria

\begin{tabular}{ll}
\hline Inclusion criteria & Exclusion criteria \\
\hline Women aged $\geq 18$ years & Earlier radiation therapy against chest or chest wall \\
Lumpectomy or mastectomy & Ulcerating cancer or infiltration to the skin \\
Postoperative, external radiation therapy: 2 Gy $\times 25$ or $2.67 \mathrm{~Gy} \times 15$ (curative intent) & \\
Able to speak and read Norwegian & \\
One or more symptoms of skin reactions at fractions $17-20$ or 8-10 & \\
Signed written informed consent &
\end{tabular}


Table 2 Characteristics of the study sample $(\mathrm{N}=7)$

\begin{tabular}{|c|c|}
\hline Demographics & $\begin{array}{l}\text { Number of } \\
\text { participants }\end{array}$ \\
\hline \multicolumn{2}{|l|}{ Additional treatment } \\
\hline Chemotherapy & 6 \\
\hline Endocrine treatment & 5 \\
\hline Immunotherapy (Herceptin) & 3 \\
\hline \multicolumn{2}{|l|}{ Lifestyle } \\
\hline Working & 2 \\
\hline Smoking & 0 \\
\hline \multicolumn{2}{|l|}{ Marital status } \\
\hline Married & 6 \\
\hline Unmarried & 1 \\
\hline Children living at home & 2 \\
\hline \multicolumn{2}{|l|}{ Treatment area } \\
\hline Breast & 1 \\
\hline Breast with lymph nodes & 1 \\
\hline Chest wall & 1 \\
\hline Chest wall with lymph nodes & 4 \\
\hline \multicolumn{2}{|l|}{ Radiation dose } \\
\hline 2 Gy $\times 25$ & 7 \\
\hline $2.67 \mathrm{~Gy} \times 15$ & 0 \\
\hline \multicolumn{2}{|l|}{ Radiation treatment parameters } \\
\hline Energy $6 \mathrm{MV}$ photon & 2 \\
\hline Energy $6 \mathrm{MV}$ photon + $15 \mathrm{MV}$ photon & 5 \\
\hline Use of bolus & 5 \\
\hline \multicolumn{2}{|l|}{ Skin type - FZ classification of skin } \\
\hline FZ 2: White skin; burns easily, tans minimally & 2 \\
\hline FZ 3: White skin; burns moderately, tans uniformly & 4 \\
\hline FZ 4: Light brown skin; burns minimally, tans easily & 1 \\
\hline
\end{tabular}

Abbreviation: FZ, Fitzpatrick.

saturation was reached after five interviews, ${ }^{20}$ but two additional interviews were conducted to ensure that saturation was achieved.

The time and place of the interview was scheduled in consultation with each participant.

\section{Data collection}

A semi-structured interview guide based on the literature was developed (Figure 1), covering five areas: experiences of the development of skin reactions, experiences of day-today life, coping strategies, experiences of information, and experiences of aftercare. The interview guide was not pilot tested. Interviews took place 2-3 weeks post-treatment in the radiation oncology department and ranged from 35 to 70 minutes. Interviews were digitally recorded.

ERA conducted all the interviews. Recordings were listened to before, during, and after the transcription process. Interviews were transcribed consecutively and verbatim by ERA and were read several times before the next interview session.

\section{Data analysis}

ERA conducted the data analysis in cooperation with GE and SE. The analysis was based on the framework established by Graneheim and Lundman, who claimed that reality can be interpreted in various ways. ${ }^{17}$ Understanding is dependent on subjective interpretation. Essential concepts are defined in Table 3. Initially, meaning units were identified and subsequently condensed, keeping the meaning close to the text (manifest content). Search for latent content was performed by interpreting the underlying meaning and identifying codes (Table 4). In total, 49 subcodes were identified and grouped into six subcategories and three categories based on commonalities. Categories were compared in reverse with the manifest text to ensure trustworthiness. Finally, the three categories were summarized in an overall main theme.

\section{Ethics}

Written informed consent was obtained from all participants included in this study. Approval was granted by the Regional Committees for Medical and Health Research Ethics (approval number 2013/2401). Participants received no economic compensation. Transcriptions were de-identified.

\section{Results}

The analysis yielded three categories: 1) unique experience of the skin; 2) it is something about the psychological aspect; and 3) experience of information, which were summarized in a comprehensive theme, "Not so bad itself, but it comes on top of everything else."

\section{Unique experience of the skin}

The physical experience of skin toxicity was described as a unique experience. The experience was new and unknown, unlike anything participants had experienced before. Two subcategories emerged: 1) experience of skin toxicity and 2) coping with skin toxicity.

\section{Experience of skin toxicity}

Reactions were described as mild or moderate. Most participants felt lucky not to experience more toxicity. Redness, itching, pain, and dry desquamation were common. In some cases, wet desquamation occurred. One participant contracted an infection and needed treatment with antibiotics.

Skin toxicity was experienced after 1-3 weeks of treatment and escalated a couple of weeks post-treatment. One participant said: 
1. Development of skin toxicity

Think back to the first time you noticed changes to the skin caused by radiation therapy. What was that like?

How did it develop/change further?

How did skin toxicity develop/change after the treatment ended?

2. Experiences of day-to-day activities

How skin toxicity affected you in your day-to-day activities? If so, in what manner?

3. Experiences of coping

What have you done to cope with skin toxicity?

Have you used any ointments (lotions, bandages, creams) in the management of skin toxicity?

4. Experiences of information

How did you get the information you needed about skin toxicity?

Were you recommended any specific ointment/management strategies?

Was the information you got in accordance with your experience?

5. Experiences of support and aftercare

What do you think support and aftercare concerning skin toxicity should consist of (time, frequency, staff)?

Have you asked someone to help you with your side effects?

Finally, is there anything else you think I should know about your experience of skin toxicity?

Figure I Semi-structured interview guide.

Table 3 Essential concepts used in the analysis

\begin{tabular}{|c|c|}
\hline Concepts & Explanation of concepts \\
\hline Manifest content & $\begin{array}{l}\text { Analysis of what the text said, dealing with the content aspect, and describing visible, obvious } \\
\text { components }\end{array}$ \\
\hline Latent content & $\begin{array}{l}\text { Analysis of what the text talked about, dealing with the relationship aspect, and involving } \\
\text { interpretation of the underlying meaning }\end{array}$ \\
\hline Meaning unit & $\begin{array}{l}\text { Words, sentences, and paragraphs containing aspects related to each other through content and } \\
\text { context }\end{array}$ \\
\hline $\begin{array}{l}\text { Condensed meaning unit: description close } \\
\text { to the text }\end{array}$ & Shortening text while preserving the core meaning \\
\hline $\begin{array}{l}\text { Condensed meaning unit: interpretation of } \\
\text { the underlying meaning }\end{array}$ & Interpretation of the underlying meaning or latent content \\
\hline Subcategory & Abstraction of condensed meaning units seen as a whole \\
\hline Category & Thread of underlying meaning through a condensed meaning unit on an interpretative level \\
\hline Overall theme & $\begin{array}{l}\text { A comprehensive understanding of all categories seen as an expression of the overall latent } \\
\text { content of the text }\end{array}$ \\
\hline
\end{tabular}

For a very long time it just itched a bit, but when I was finished with the radiation, it became very red and brown and $[\ldots]$. Then it was hardly itchy at all [...]. [Participant 4]

In some cases, the physical pain caused by skin toxicity prevented participants from sleeping properly: $[\ldots]$ when you break a leg or something, you'll get [...] a hoop to put the blanket on. I would like one of those, because I woke up every time the blanket touched my skin. [Participant 3]

Experience of skin toxicity did not always comply with the visual appearance of reactions: 
Table 4 Analysis procedure from a manifest to a latent level

\begin{tabular}{|c|c|c|c|c|}
\hline \multicolumn{2}{|l|}{ Manifest level } & \multicolumn{3}{|l|}{ Latent level } \\
\hline Meaning unit & $\begin{array}{l}\text { Condensed meaning unit: } \\
\text { description close to the } \\
\text { text }\end{array}$ & $\begin{array}{l}\text { Condensed meaning unit: } \\
\text { interpretation of the } \\
\text { underlying meaning (code) }\end{array}$ & Subcategory & Category \\
\hline $\begin{array}{l}\text { Cannot look at the } \\
\text { Internet to see what } \\
\text { people say. You can find } \\
\text { exactly what you want } \\
\text { and make it to whatever } \\
\text { you want. Cannot listen } \\
\text { to what others tell you. } \\
\text { I received the information } \\
\text { I needed from the } \\
\text { department and trusted } \\
\text { that }\end{array}$ & $\begin{array}{l}\text { Cannot use the Internet or } \\
\text { others when searching for } \\
\text { information. } \\
\text { Trusts the information } \\
\text { given at the department }\end{array}$ & $\begin{array}{l}\text { Information given by } \\
\text { health care providers is } \\
\text { considered trustworthy }\end{array}$ & $\begin{array}{l}\text { Search for trustworthy } \\
\text { information }\end{array}$ & Experience of information \\
\hline
\end{tabular}

"You are so red, so red!" they told me. But when you don't feel it, it doesn't matter. [Participant 5]

Now it doesn't hurt any more. It is just very, very red.

[Participant 6]

Participants found it difficult to describe their experiences of skin toxicity. It was compared with being sunburned, although several participants emphasized that such a comparison was inadequate.

\section{Coping with skin toxicity}

Physical changes and symptoms were managed using creams, lotions, bandages, and salt water. Perfume, deodorant, jewellery, and soap were avoided. All participants took precautions about clothing; clothes had to protect against the sun and be soft to wear. Participants were creative about overcoming challenges concerning clothes, as one said:

I had an old turtleneck [...]. I just removed the sleeves, then

I have $[\ldots]$ you know the neck when going for a swim [...].

Using a scarf in the sea wasn't any good. [Participant 2]

Another tried covering her skin with bandages, but gave up to avoid using tape on sore skin.

The time of year seemed to influence psychological distress and impaired day-to-day function as demonstrated in the following two comments:

It's tougher when it is sunny outside, of course [...] and hot. Because we are [...] on one side you want to be outside when the weather is good. We are not so spoiled [...] sort of, in this area. On the other hand, you cannot go outside and enjoy it [...]. [Participant 1]

Cleaning, for example. It is not necessary to do all the rooms in 1 day, I learned rather quick [...]. [Participant 7]
Participants emphasized the importance of provision and repetition of concrete advice about skin management and protection. One participant said:

It's strange regarding the information you receive. You have to receive it many times to remember it. I had to look at the written information several times. [Participant 3]

\section{It is something about the psychological aspect}

It became evident that the physical experience did not represent the main problem. Most participants used a phrase with a similar meaning to "It is something about the psychological aspect." Two subcategories emerged: 1) a source of uncertainty and 2) need for support.

\section{A source of uncertainty}

All participants reported that skin toxicity was not a problem in the context of the importance of treatment. However, it led to uncertainty to some extent. Participants had no qualifications or experience to imagine how reactions would develop during and after treatment. They could not tell if reactions were normal or not. One participant said:

I have been sunburned before, so I know how that develops, but you cannot know for certain when it's caused by something else. You can see it looks like it, but you are not certain that it will develop the same way, how long it will take [...] how big a problem it will be. [Participant 1]

One participant used sunscreen one weekend, but read that she should not use sunscreen on the treatment area during the treatment period. She was terrified, slept badly, and was 
frightened that the next radiation dose would be reduced. She was worried she had ruined her treatment.

Different thoughts about the future were prominent. Some participants were afraid of doing something wrong resulting in more pain or health problems:

Isn't there something with deodorants and perfumes and stuff like that; I should not use these things [...] for how long? I've talked to others who have received radiation, and they have been very careful with soaps and deodorants for years afterwards. And I thought: I have to ask. I don't want to make any mistakes. [Participant 5]

I'm so scared for $[\ldots]$. I understand that it is skin cancer $[\ldots]$ that you may get that [...]. I've had enough! I don't want that. So I try to cover myself! [Participant 2]

Most participants reported that covering the irradiated area from the sun was challenging, and they did not have knowledge about how to manage it. One said:

I haven't found out if it is enough with just sunscreen or with a scarf or how [...] there are no clear guidelines on this topic $[\ldots]$. It might be the greatest challenge for me $[\ldots]$ to cover the area properly. [Participant 4]

One participant highlighted that the restrictions were frustrating and were a constant reminder of what she had been through. She would not feel normal before she could.

Throw away the scarf and be like everybody else.

[Participant 3]

\section{Need for support}

Participants emphasized the importance of support and described how lack of support could make it more difficult to cope with skin toxicity.

One participant described how the reactions affected her relationship with her husband:

Had to be very careful. Couldn't come near it, because it hurts so bad [...]. I have been very lucky to have a nice man. [Participant 3]

Another described how the radiation therapists treated her:

They take care of you, when it is your turn. And everybody else has to wait. And that's a good experience [...]. It has to do with feelings of security, it has to do with feelings of calm $[\ldots]$ in my head: coping with the situation. [Participant 6]
One comment underlined the importance of support in day-to-day activities such as vacuuming and cleaning:

[...] of course, for those who are alone it is a problem!

[Participant 7]

Supportive care could also involve managing individual needs that appeared to be irrelevant to skin toxicity. One woman said it was important to receive treatment at 8 o'clock every morning, so that she did not have to see other patients who seemed so sick. This helped her manage her own problems in a better way.

\section{Experience of information}

Skin reactions generated a need for information. Adequate information was necessary to reduce uncertainty and to ensure feelings of safety and predictability. Two subcategories emerged: 1) search for trustworthy information and 2) aftercare.

\section{Search for trustworthy information}

Many information sources, including spouses, physiotherapists, general practitioners (GPs), pharmacists, other cancer patients, and the Internet, were used. However, the primary source of information was oral and written information provided by the cancer oncology department. It was considered trustworthy and, therefore, preferred. As one participant emphasized:

I can't even look at the Internet for information. No, I can't.

Then you'll get a sort of agony at once because there's so much nonsense there. So all information you get from here is very important! [Participant 4]

Some participants wished for extensive information. However, to use this information, they needed to experience their personal reactions:

[...] It was very theoretical before you really stood in the middle of it. [Participant 1]

\section{Aftercare}

Participants were encouraged to contact the oncology department when necessary. Detailed information about establishing such contact was desired. They needed to know where and when to call, and who would answer. Uncertainty about whether to call the hospital or their GP was a problem.

Some wanted scheduled aftercare appointments during the first weeks post-treatment. It was not important who 
conducted such sessions (physicians, radiation therapists, or nurses). The primary role of aftercare was described as confirming that reactions were normal and providing general advice and support. One participant described her feelings post-treatment:

When you suddenly get home and don't have the security any more, you are always wondering when looking in the mirror "Should I have done something? Is this the way it's supposed to be?" [Participant 7]

Another described her feelings after her treatment ended as sort of a middle state:

You'll wonder, what on earth am I going to do? Because, you are $[. .$.$] sort of not sick, but you are not quite well after$ all [...]. [Participant 4]

\section{Not so bad itself, but it comes on top of everything else}

The comprehensive understanding of the presented categories provides new and valuable perspectives in relation to information needs, physical and psychological influence of skin toxicity, patients' thoughts about the future, aftercare, and patients' expectations to health care providers. Furthermore, the categories give the foundation to the overall latent theme, "The skin toxicity is not so bad itself, but it comes on top of everything else." Acute radiation-induced skin toxicity influences many dimensions of participants' lives and underlines the importance of a holistic approach and perspective.

\section{Trustworthiness}

Qualitative research of high standard must be credible, dependable, and trustworthy. ${ }^{16,17}$ Therefore, we used the consolidating criteria for reporting qualitative research: a 32 -item checklist for interviews and focus groups. ${ }^{20}$ With the exception of participating in two of the computed tomography examinations used for treatment planning, ERA was not involved in the planning process or in the treatment of the participating women.

One of the eligibility criteria in this study was skin reactions at the start of the last treatment week. In retrospect, the criteria made it difficult to include patients receiving treatment over a 3-week period as it might have been too soon for these patients to develop symptoms. Thus, our findings might not be directly transferable to patients with a 3-week course. However, there are reasons to believe that the essence of our findings, such as need for information and support, would be of importance. The small sample and the homogenous demographic distribution lead to limitations of transferability. Although a larger sample size might have supported more in-depth understanding, the participants offered rich and varied descriptions of issues of central importance to the purpose of the study. We thus assess the data from the interviews to be sufficient to bring new understandings to a topic that hitherto has received sparse attention in this field.

\section{Discussion}

The purpose of this study was to investigate patients' experiences of acute skin toxicity following radiation therapy for breast cancer. To our knowledge, this study is the first study investigating in-depth post-treatment experiences of skin toxicity. Systematic aftercare is often not provided in this period, even though skin toxicity is expected to increase and reach a peak during this period. ${ }^{14}$ This study was conducted fairly early post-treatment to investigate patients' experiences in this time period, yielding valuable knowledge of patient experiences and needs. However, further studies are necessary to capture the whole experience of skin toxicity.

Most of the literature published consists of effect studies evaluating specific products used for treating or preventing skin toxicity. Evaluating visual appearance has traditionally been the most common way to describe skin toxicity. ${ }^{1,4,10}$ Schnur et al noted a lack of studies exploring subjective experiences. ${ }^{4}$ A previous interview-based study performed during the last week of treatment described how skin toxicity may affect multiple dimensions of patients' lives: ${ }^{5}$ visual skin changes were reported as Radiation Therapy Oncology Group grade 1 (faint erythema, dry desquamation) or 2 (tender or bright erythema, patchy moist desquamation) in $95 \%$ of the participants. Interestingly, physical changes such as pain and changes of skin color seemed to be central to patient experiences. One participant in that study would refuse radiation if needed in future owing to skin toxicity, while another considered quitting treatment owing to pain. ${ }^{5}$ We intended to investigate patient experience and did not perform skin assessment during the interviews. Reactions were mainly described as Radiation Therapy Oncology Group grade 1 or 2. Interestingly, the physical experience of skin toxicity was not a problem in the context of the importance of treatment for our participants.

In this particular hospital, patients are given written information describing development of skin toxicity and advice for use of ointments. Patients are advised to use perfume-free moisturizing lotion or a silicone-based dressing, avoid deodorant at the treatment side, and avoid friction from clothing. This is considered as standard care. Patients 
are encouraged to contact the department or their GP if they develop fever or infection. The need for information has been suggested to be strongest before radiation therapy commences. ${ }^{11,12}$ This is partly consistent with our findings. Interestingly, we found that patients' main concern was a feeling of uncertainty and need for predictability and support, not the actual management of the skin toxicity. Our participants reported that it was not easy to understand and use the information provided before they developed skin reactions. Thus, the need for information might also be strong post-treatment. Skin toxicity was described as "very theoretical before you stood in the middle of it." This finding illustrates that disparities between health care provider and patient experiences of information and support might exist. Furthermore, this finding is particularly important as the oncology department staff was considered as the most trustworthy source of information.

Adequate protection from the sun led to uncertainty. Several women were afraid of inducing severe consequences, such as poor treatment results or secondary cancer. Fear of secondary cancer following radiation therapy was also found in other studies. ${ }^{5,21}$ Patients might follow instructions from health care providers blindly and strictly due to fear and uncertainties. This might lead to distress. Furthermore, we found that skin toxicity might act as a reminder of sickness and treatment, since extended sun protection will be necessary for several years. To our knowledge, this aspect has not previously been reported.

Future research should include more patient characteristics such as body mass index, breast volume, treatment technique, previous skin conditions, and comorbidities. We also recommend to focus on longitudinal experiences post-treatment, including psychological changes and coping mechanisms. Inclusion procedures should ensure inclusion of patients receiving treatment over a 3-week period, as this practice is becoming more frequent. ${ }^{22}$ There might be even more need for support in this group, since the patients may develop most reactions at home when they do not have the daily support received during treatment.

Quotations used to support the presentation of results enhanced credibility, as they gave the reader direct access to some of the manifest content used in the analysis.

\section{Clinical implications}

Visual evaluation of skin reactions is important, and consensus about how to report acute skin toxicity is required. However, patient characteristics such as age, time of year, other treatments, irradiated area, family or relationship status, and smoking have been reported to affect the experience of skin toxicity. ${ }^{4,5,15,23}$ Similarly, we found that physiological reactions were experienced differently, for example, treatment during the summer and lack of support were associated with greater distress.

As demonstrated, health care providers must understand that the reactions may exceed the visual component and may affect patients in many different ways. Patient experiences may not necessarily be consistent with visual appearances. Knowledge about a patient's context may help in understanding their behavior. Reducing worries that appear to be irrelevant or facilitating patient needs may help patients to cope with their reactions.

Oral and written information provided to patients must be consistent and repeated. Continuity of care is a core value of general practice and will be particularly important for patients in need of coordinated health care services from multiple providers. ${ }^{24}$ To have a primary radiation therapist as their main contact could strengthen the patient's feeling of safety and support and ease the pathway between health care provider and patient post-treatment. An optional telephone appointment could provide an opportunity to repeat information and offer support. See Table 5 for our recommendations for clinical practice. These recommendations should be evaluated in future research.

\section{Conclusion}

Acute skin toxicity following breast cancer treatment may affect many dimensions of patients' lives. Experiences of skin toxicity are complex, individual, and not necessarily consistent with visible changes of the skin. A holistic approach is necessary to provide treatment and support according to patients' individual needs.

\section{Acknowledgments}

We would like to express our gratitude to Anne Gro Buerskog for helping to recruit participants and to Professor Erling Stranden for guidance during the process. Finally, we would like to thank all the participants for sharing their experience. This work was supported by The Norwegian Society of Radiographers (096-096.ap14), Stavanger University Hospital, Norway (2010/969 - 26771/2014), and by University College of Southeast Norway (911770709).

\section{Disclosure}

The authors report no conflicts of interest in this work. 
Table 5 Recommendation for clinical practice

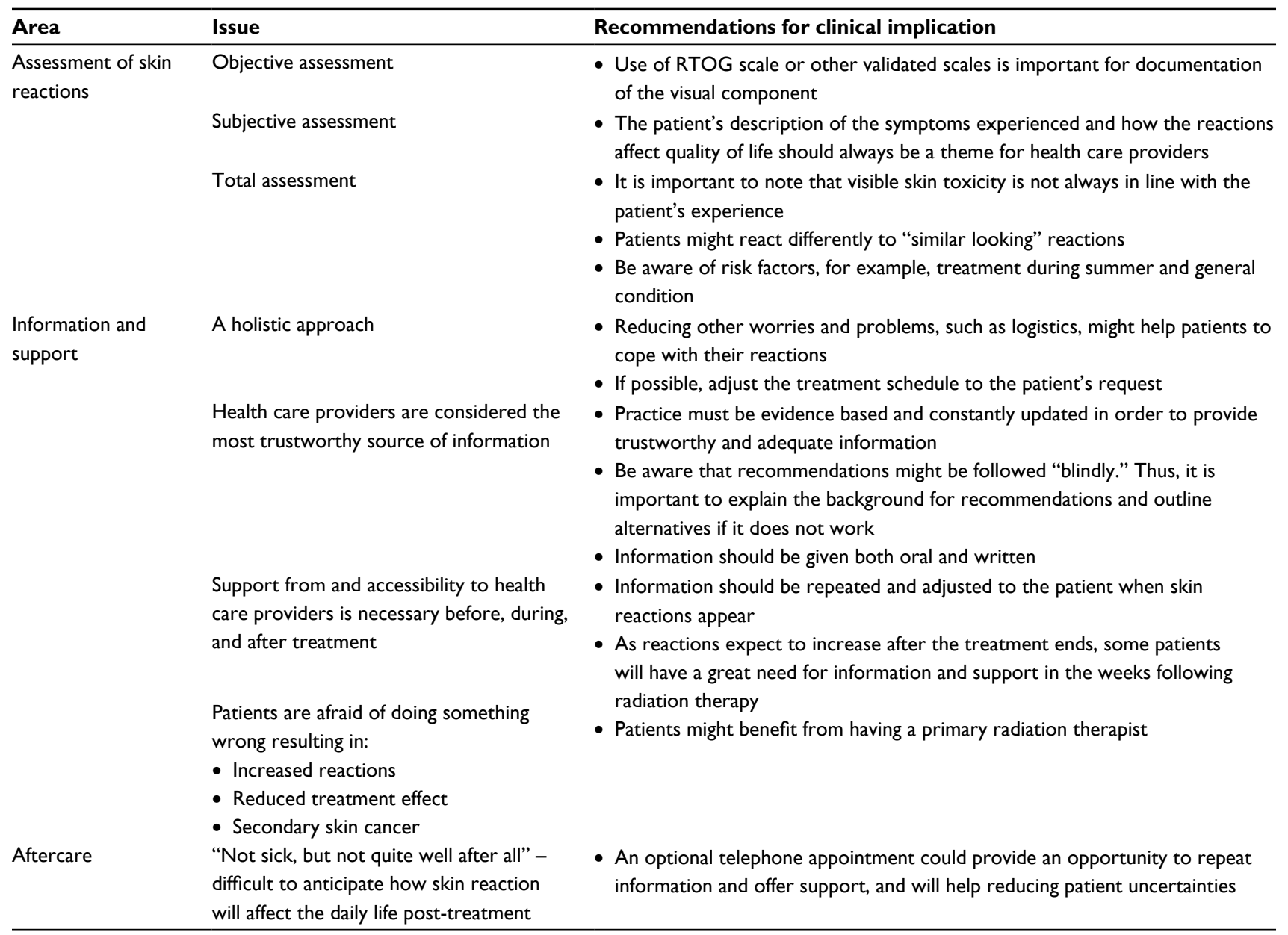

Abbreviation: RTOG, Radiation Therapy Oncology Group.

\section{References}

1. Butcher K, Williamson K. Management of erythema and skin preservation; advice for patients receiving radical radiotherapy to the breast: a systematic literature review. J Radiother Pract. 2011;11(1): 44-54.

2. Feight D, Baney T, Bruce S, McQuestion M. Putting evidence into practice: evidence-based interventions for radiation dermatitis. Clin J Oncol Nurs. 2011;15(5):12.

3. Kumar S, Juresic E, Barton M, Shafiq J. Management of skin toxicity during radiation therapy: a review of the evidence. $J$ Med Imaging Radiat Oncol. 2010;54(3):264-279.

4. Schnur JB, Love B, Scheckner BL, Green S, Wernicke AG, Montgomery GH. A systematic review of patient-rated measures of radiodermatitis in breast cancer radiotherapy. Am J Clin Oncol. 2011;34(5): 529-536.

5. Schnur JB, Ouellette SC, Dilorenzo TA, Green S, Montgomery GH. A qualitative analysis of acute skin toxicity among breast cancer radiotherapy patients. Psychooncology. 2011;20(3):260-268.

6. McQuestion M. Evidence-based skin care management in radiation therapy: clinical update. Semin Oncol Nurs. 2011;27(2):e1-e17.

7. Knobf MT, Sun Y. A longitudinal study of symptoms and self-care activities in women treated with primary radiotherapy for breast cancer. Cancer Nurs. 2005;28(3):210-218.

8. Sjovall K, Strombeck G, Lofgren A, Bendahl PO, Gunnars B. Adjuvant radiotherapy of women with breast cancer - information, support and side-effects. Eur J Oncol Nurs. 2010;14(2):147-153.
9. Merckaert I, Libert Y, Messin S, Milani M, Slachmuylder JL, Razavi D. Cancer patients' desire for psychological support: prevalence and implications for screening patients' psychological needs. Psychooncology. 2010;19(2):141-149.

10. Noble-Adams R. Radiation-induced skin reactions 2: development of a measurment tool. Br J Nurs. 1999;8(18):1208-1211.

11. Halkett GK, Kristjanson LJ, Lobb EA. "If we get too close to your bones they'll go brittle": women's initial fears about radiotherapy for early breast cancer. Psychooncology. 2008;17(9):877-884.

12. Halkett GK, Kristjanson LJ, Lobb E, et al. Information needs and preferences of women as they proceed through radiotherapy for breast cancer. Patient Educ Couns. 2012;86(3):396-404.

13. Dörr W. Time factors in normal-tissue responses to irradiation. In: Joiner MC, Van der Koegel A, editors. Basic Clinical Radiobiology. 4th ed. London: Hodder Arnold; 2009:149-157.

14. Cumming J, Routsis D. Are improvements needed in the management of severe acute skin reactions following completion of breast radiotherapy? A discussion of some possible service options. J Radiother Pract. 2009;8(1):11-16.

15. Stanton AL. What happens now? Psychosocial care for cancer survivors after medical treatment completion. J Clin Oncol. 2012;30(11): 1215-1220.

16. Malterud K. Qualitative research: standards, challenges, and guidelines. Lancet. 2001;358(9280):483-488.

17. Graneheim UH, Lundman B. Qualitative content analysis in nursing research: concepts, procedures and measures to achieve trustworthiness. Nurse Educ Today. 2004;24(2):105-112. 
18. Elo $\mathrm{S}$, Kyngas $\mathrm{H}$. The qualitative content analysis process. $J A d v$ Nurs. 2008;62(1):107-115.

19. Krippendorff K. Content Analysis: An Introduction to Its Methodology. 2nd ed. United States of America: Sage Publications; 2004.

20. Tong A, Sainsbury P, Craig J. Consolidated criteria for reporting qualitative research (COREQ): a 32-item checklist for interviews and focus groups. Int J Qual Health Care. 2007;19(6):349-357.

21. Schnur JB, Ouellette SC, Bovbjerg DH, Montgomery GH. Breast cancer patients' experience of external-beam radiotherapy. Qual Health Res. 2009;19(5):668-676.
22. Senkus E, Kyriakides S, Ohno S, et al; ESMO Guidelines Committee. Primary breast cancer: ESMO clinical practice guidelines for diagnosis, treatment and follow-up. Ann Oncol. 2015;26(Suppl 5):v8-v30.

23. Hofso K, Rustoen T, Cooper BA, Bjordal K, Miaskowski C. Changes over time in occurrence, severity, and distress of common symptoms during and after radiation therapy for breast cancer. J Pain Symptom Manage. 2013;45(6):980-1006.

24. Haggerty JL, Reid RJ, Freeman GK, Starfield BH, Adair CE, McKendry R. Continuity of care: a multidisciplinary review. BMJ. 2003;327(7425):1219-1221.
Journal of Multidisciplinary Healthcare

\section{Publish your work in this journal}

The Journal of Multidisciplinary Healthcare is an international, peerreviewed open-access journal that aims to represent and publish research in healthcare areas delivered by practitioners of different disciplines. This includes studies and reviews conducted by multidisciplinary teams as well as research which evaluates the results or conduct of such teams or health care processes in general. The journal covers a very wide range of areas and welcomes submissions from practitioners at all levels, from all over the world. The manuscript management system is completely online and includes a very quick and fair peer-review system. Visit http://www.dovepress.com/ testimonials.php to read real quotes from published authors. 